\title{
Rare isolated myopia
}

INSERM

\section{Source}

INSERM. (1999). Orphanet: an online rare disease and orphan drug data base. Rare isolated myopia. ORPHA:98619

Rare isolated myopia is a rare, genetic, refraction anomaly disorder characterized by nonsyndromic severe myopia, which may be associated with cataract and vitreoretinal degeneration (retinal detachment) that may lead to blindness. 